\title{
Special Issue: Control and Optimization
}

\author{
Rentsen Enkhbat • Ider Tseveendorj
}

Received: 30 July 2011 / Accepted: 12 August 2011 / Published online: 30 August 2011

(C) Springer-Verlag 2011

The International Conference on Optimization, Simulation and Control (COSC2010) was held during July 25-28, 2010 in Ulaanbaatar, Mongolia. The conference was endorsed by

- National University of Mongolia,

- The Institute of Mathematics of Mongolia,

- The Mongolian Academy of Sciences,

- Mongolian Science Technology Foundation,

- Mongolian University of Science and Technology,

- Embassy of the United States in Mongolia,

- University of Versailles Saint-Quentin-en-Yvelines and

- PRiSM-CNRS, France.

This meeting was the third event in the series of conferences on optimization and control in Mongolia started in 2002. The second event took place in 2007 and contributions of these preceding conferences appeared respectively in a volume entitled "Optimization and Optimal Control" published by the World Scientific Publishers [3] and in a special issue of the journal "Optimization" [2], in "Springer Optimization and Its Applications" serie [1].

This time the presentations were done by speakers coming from 16 countries. The participants were invited to submit their contribution to a special issue.

\footnotetext{
R. Enkhbat

School of Economic Studies, National University of Mongolia, Ulaanbaatar, Mongolia e-mail: renkhbat46@yahoo.com

I. Tseveendorj $(\varangle)$

Laboratoire PRiSM, Université de Versailles, 45, avenue des États-Unis,

78035 Versailles Cedex, France

e-mail: Ider.Tseveendorj@prism.uvsq.fr
} 
This special issue contains a selective collection of carefully refereed papers based on talks presented during the third conference. These papers deal with both theoretical and practical aspects of Optimization and Control.

We would like to express our thanks to the organizations listed above which have given their sponsorship to this meeting.

We also would like to extend our gratitude to

- the authors, the participants who have shown their interest in this conference,

- the referees who have accepted the difficult task of reading and selecting papers,

- our co-chairs, colleagues of the Organization Committee,

- Professor Panos Pardalos, the Editor-in-chief of the journal "Optimization Letters", who has accepted to publish this special issue.

\section{References}

1. Chinchuluun, A., Pardalos, P.M., Enkhbat, R., Tseveendorj, I. (eds.).: Optimization and Optimal Control. Springer Optimization and Its Applications, vol. 39. Springer, New York (2010) (theory and applications)

2. Enkhbat, R., Chinchuluun, A., Tseveendorj, I.: Preface (Special issue: second international conference on optimalization and optimal control). Optimization, 58(7), 727-728 (2009) (held in Ulaanbaatar, July 17-20, 2007)

3. Pardalos, P.M., Tseveendorj, I., Enkhbat, R. (eds.): Optimization and Optimal Control. Series on Computers and Operations Research, vol. 1. World Scientific, River Edge (2003) (papers from the international conference held in Ulaanbaatar, August 13-17, 2002) 